\title{
DOS MANUAIS ÀS REDES SOCIAIS:A ESCRITA DE PRESCRIÇÕES DE CIVILIDADE NO TEMPO PRESENTE
}

\author{
MANUALS TO SOCIAL NETWORKS: THE WRITING OF CIVILITY \\ PRESCRIPTIONS IN THE PRESENT TIME
}

\begin{abstract}
Márcia Regina dos Santos ${ }^{1}$
RESUMO: O presente estudo tem como foco discutir a constituição de ego-documentos em suporte digital com intuito formativo. Para tanto, foram mobilizadas como fontes de pesquisa os perfis da rede social facebook de duas autoras de manuais de etiqueta e boas maneiras. A produção e circulação de manuais com prescrições de civilidade como uma prática formativa tem passado pela remodelação de formas, discursos e suportes, movimento que possibilita a sua abordagem à luz da história do tempo presente. As autoras Glória Kalil e Claudia Matarazzo, se consagraram como escritoras que se debruçaram sobre a área das civilidades. Na condição de autoras adaptadas ao meio digital, uma vez que, esse processo não fez parte $\mathrm{da}$ formação das gerações as quais pertencem, suas redes sociais se constituem em acervos pessoais alternativos, pelo caráter não material, publicizados para forjar determinada exemplaridade de como ser e permanecer em sociedade. As transformações ocorridas no âmbito da circulação das informações, intensificadas pelo uso da internet, foram apropriadas pelas autoras e a produção de manuais recebeu novos contornos, diferentes dos diversos livros publicados sobre o assunto. A análise de suas redes sociais possibilitaram evidenciar as diferentes formas e suportes nos quais se encontram as prescrições de civilidade no século XXI, bem como, as tensões existentes entre passados que persistem e presentes que se impõem, configurando uma convivência peculiar e conflituosa.
\end{abstract}

Palavras-chave: Civilidade. Acervos digitais. Tempo presente.

ABSTRACT: The present study focuses on discussing the costitution of ego-documents in digital format for formative purposes. For that, the profiles of the social network facebook of two authors of manuals of etiquette and manners were mobilized as sources of research. The production and circulation of manuals with prescriptions of civility as a formative practice has gone through the remodeling of forms, discourses and supports, a movement that enables its approach in light of the history of the present time. The authors Glória Kalil and Claudia Matarazzo, were consecrated as writers who looked at the area of civilities. As authors adapted to the digital environment, since this process did not form part of the formation of the generations to which they belong, their social networks constitute alternative personal collections, due to the non-material nature, publicized to forge a certain exemplarity of how to be and remain in society. The transformations occurred in the scope of information circulation, intensified by the use of the Internet, were appropriated by the authors and the production of manuals received new contours, different from the several books published on the subject. The analysis of their social networks made it possible to highlight the different forms and supports in which the prescriptions of civility are found in the 2ist century, as well as the tensions between persistent and present pasts that impose themselves, configuring a peculiar and conflictive coexistence.

\footnotetext{
I Doutoranda pelo Programa de Pós-Graduação em História da Universidade do Estado de Santa Catarina (UDESC- Florianópolis- SC/BR), na Linha de Pesquisa Políticas de memória e narrativas históricas. Bolsista do Programa de Bolsas de Monitoria de Pós-Graduação - PROMOP. E-mail: marciao75@gmail.com.
} 
Keywords: Civility. Digital collections. Present time.

\section{INTRODUÇÃO}

5 resoluções para um feliz 2016.

1. ECONOMIZAR: água, dinheiro, ostentação, palavras impensadas, faladas ou blogadas.

2. FOCAR nas coisas essenciais para cada uma de nós: família, trabalho, amigos, ginástica, aulas de inglês.

3. NÃO RECLAMAR o tempo todo de tudo: do calor, do governo, do trânsito; pode notar que quanto mais você reclama do calor, mais quente fica.

4. IR ATRÁS de pelo menos uma coisa que divirta, instrua, faça bem para a saúde; uma aula, um curso, uma atividade, um grupo.

5. PEGAR LEVE na internet e nos smartphones com menos opiniões, menos fotos, menos selfies, menos face, menos mimimi. ${ }^{2}$

Ao aproximar-se do início do ano de 2016, mais precisamente, no dia 4 de janeiro, a autora, consultora, jornalista e formadora de tendências Gloria Kalil, publicou em seu perfil da rede social facebook os cinco princípios básicos que, segundo sua concepção, tornariam o ano que se iniciava mais feliz. As dicas publicizadas no ambiente virtual não se configuraram em regras de convívio, entretanto, possivelmente, foram lidas e apropriadas por um número incalculável de pessoas, uma vez que, foram compartilhadas 5.326 vezes $^{3}$. Pensando a partir da premissa que as sociedades do século XXI utilizam progressivamente os meios digitais para entreter-se, informar-se e configurar pertencimento, como é possível pensar o impacto de publicações como essa sobre os usuários ${ }^{4}$ de redes socias? Não há uma resposta precisa e nem simples. As informações circulantes no ambiente digital, especialmente em redes socias como o facebook, impactam diariamente milhares de pessoas e, a constituiçao de um acervo pessoal de informações - sob diversos pretextos - pode assumir dimensões que, facilmente, se configuram em exercício público de formar comportamentos, opiniões e civilidades. O presente estudo tem como foco discutir a costituição de ego-documentos ${ }^{5}$ em suporte digital com intuito formativo.

${ }^{2}$ Disponível em: https://www.facebook.com/GloriaKalilChic/ . Acesso em: 16 abr. 2018.

3 A funcionalidade da interface da página virtual identificada como "compartilhamento" permite que leitores do conteúdo publicado possam replicar o mesmo em suas páginas da mesma rede social, nesse caso o facebook.

${ }^{4}$ No sentido de utilizar os termos que definem padrões no âmbito da internet, as nomenclaturas são iguais as utilizadas nas redes sociais, até mesmo por que, no século XXI têm se configurado em linguagem comum aos utilizadores de ambientes virtuais, de forma geral. Ressalto que o público definido como "usuários" compreende todas as pessoas que têm acesso as informações veiculadas na internet.

5 Compreendidos aqui a partir da perspectiva de que dizem respeito às experiências pessoais e se constituem no intuito de guardar a si mesmo. $O$ conceito de ego-documento foi elaborado pelo historiador holandês Jacob Presser, em 1958, e, posteriormente debatido e aprofundado sob diversas óticas e para pensar diversos suportes. O autor James Amelang, destaca na apresentação do dossiê De la autobiografia a 
Para tanto, foram mobilizadas como fontes de pesquisa os perfis da rede social facebook de duas jornalistas, autoras de manuais de etiqueta e boas maneiras: Gloria Kalil e Claudia Matarazzo. A produção e circulação de manuais com prescrições de civilidade como uma prática formativa tem passado pela remodelação de formas, discursos e suportes, movimento que possibilita a sua abordagem à luz da história do tempo presente, portanto, "Trata-se aqui de um eixo temporal móvel, cujo ponto de origem é sempre a geração atual e que, por isso, se desloca constantemente" (KOSELLECK, 2014, p. 269). As referidas autoras se consagraram como escritoras que se debruçaram sobre a área das civilidades, debateram a remodelação dos costumes e as novas demandas para conviver em sociedade. Na condição de autoras adaptadas ao meio digital, uma vez que, esse processo não fez parte da formação das gerações as quais pertencem, suas redes socias se constituem em acervos pessoais alternativos, pelo caráter não material, publicizados para forjar determinada imagem sobre si e, nesses casos, uma exemplaridade de como ser e permanecer em sociedade.

A criação de perfis integrados às redes sociais permite a constituição de acervos pessoais ou institucionais com os mais variados intuitos. É possível guardar no ambiente virtual desde documentos de caráter biográfico como fotos de si, da família, de momentos selecionados para fazerem parte de uma memória, até conteúdos de cunho profissional ou comercial. Para além disso, autoras e autores das páginas tem como escolher as formas como vão tornar as informações públicas, e, no caso das duas autoras, ambas, ou as acessorias que administram seus perfis (prática comum quando as redes são utilizadas com intuito profissional), permitem que os conteúdos estejam acessíveis a todos os usuários. Com objetivo de evidenciar os usos e as formas de constituição de ego-documentos em ambientes virtuais, a abordagem dos documentos foi configurada a partir da História do Tempo Presente (ROUSSO, 1991,2009; HARTOG, 2013; DOSSE, 2001, 2013), sob a perspectiva de estratos do tempo, a qual "permite separar analiticamente os diversos planos temporais em que as pessoas se movimentam, os acontecimentos se desenrolam e os pressupostos de duração mais longa são investigados" (KOSELLECK, 2014, p. 19). A problematização foi elaborada a partir das interlocuções

los ego-documentos: un fórum abierto, da revista Cultura Escrita d Sociedad (2005) que os ego-documentos se referem a "la diversidad de las formas de expresión escrita de los sentimientos y experiencias personales. Desde su punto de vista, un ego-documento es un texto, de cualquier forma o tamaño, 'en el que se esconde o descubre deliberada o accidentalmente un ego"' (AMELANG, 2005, p. 17). Nessa esteira, como documentos alocados em páginas pessoais de redes sociais, se inscrevem na perspectiva acerca da constituição de arquivos pessoais pensada por Phillipe Artières, na qual "arquivar a própria vida é desafiar a ordem das coisas: a justiça dos homens assim como o trabalho do tempo" (ARTIERES, i998, p. 31). Ainda que, as intuito de divulgar suas atividades profissionais, bem como, alongar a vida de suas produções bibliográficas sobre o tema da etiqueta e boas maneiras. 
registradas nas redes sociais de Glória Kalil e Claudia Matarazzo as quais dão a ver as diversas formas de identificação entre ego- documentos, constituídos como imagens de si, e os interlocutores que se interessam por esse tipo de narrativa. Sobre as transformações na constituição do "eu" em relação ao "outro" ocorridas após a ampla vulgarização e as muitas apropriações das possibilidades oferecidas pelo ambiente virtual da internet debatidas pelo sociólodo David Riesman, a autora Paula Sibilia pondera que,

Esta mutação revelou um deslocamento dos eixos em torno do qual cada sujeito constrói o que é: um deslize de "dentro" de si mesmo para "fora" daquela essência antiga que estava escondida nas próprias entranhas. Ou mais precisamente, um deslocamento desse núcleo do eu localizado no profundezas íntimas do "caráter" individual em relação a tudo que outros podem observar e verificar como a "personalidade" do sujeito que mostra e interage no mundo. Portanto, o sociólogo referiu-se ao abandono de um modelo de subjetividade introdutória e o surgimento iminente de um novo tipo, que seria alterado ou orientado para os outros ${ }^{6}$.

A circulação de informações no ambiente virtual da internet tem como característica importante a velocidade e dinamicidade com que transitam as publicações nos inúmeros sistemas de dados que compõem a rede. As fontes utilizadas nesse estudo estão alocadas nas páginas do facebook das referidas autoras e, para efeito de estabilização e sistematização de dados empíricos para proceder a análise, foram selecionadas a partir de publicações escritas nos perfis e os dados quantitativos colhidos em cada perfil. Para a consecução do objetivo do estudo os conteúdos serão abordados como elementos elucidativos da utilização das construções de si por meio de ego- documentos que circunscreve as interlocuções identificadas em cada uma das páginas pesquisadas e coletadas até o dia 19 de maio de 2018 .

As autoras selecionadas para este estudo entremearam suas carreiras profissionais pela produção de livros de etiqueta e boas maneiras. Para além de outras atividades escritas, como a participação de colunas em revistas e jornais, as duas mulheres acompanharam o movimento tecnológico e investiram na produção de materiais para o ambiente virtual, assim como, artigos e vídeos. Dessa produção, foram problematizados as formas como foram e continuam sendo contituidos os perfis, bem como, as publicações que se alocam sob a perspectiva de egodocumentos, pois, "ao arquivar sua vida o guardador imortaliza uma época e produz

\footnotetext{
${ }^{6}$ Tradução livre da autora, do original "Esa mutación revelaba un desplazamiento de los ejes en torno de los cuales cada sujeto edifica lo que es: un deslizamiento desde "adentro" de uno mismo hacia "afuera" de aquella antigua esencia que se ocultaba en las propias entrañas. $\mathrm{O}$, más precisamente, un desplazamiento de aquel núcleo del yo situado en las profundidades íntimas del "carácter" individual, hacia todo aquello que los demás pueden observar y constatar como la "personalidad" del sujeto que se muestra e interactúa en el mundo. Por eso, el sociólogo aludía al abandono de un modelo de subjetividad introdirigida y al inminente surgimiento de un nuevo tipo, que sería alterdirigido u orientado hacia los otros" (SIBILIA, 2009, p. 312).
} 
representações e marcas de si mesmo. Os objetos autobiográficos que compõem um arquivo pessoal materializam, assim, uma proposta de leitura associada à imagem que se quis preservar de si mesmo" (CUNHA, 2017, p. 191). Nesse sentido, as publicações atendem as funções profissionais da mesma forma que exprimem as representações desejadas pelas autoras. $\mathrm{Na}$ condição de mulheres/autoras adaptadas ao meio digital, uma vez que, esse processo não fez parte da formação das gerações a que pertencem, suas redes socias se constituem em acervos pessoais alternativos, pelo caráter não material, publicizados para forjar determinada forma de ser e permanecer em sociedade, bem como, referências no tema de suas obras. A ocupação de espaço nesse suporte de divulgação, privilegiado pelo alcance e pelas facilidades de acesso $e$ portabilidade na sociedade do século XXI, possibilita pensar sobre a tensão de passados e futuros no entendimento sobre um presente. Dessa forma, os acervos pessoais virtuais se apresentam, assim como os cadernos e diários pessoais, como recursos no intento de guardar-se, perenizarse e dar-se a ver no presente e na posteridade.

As duas autoras mantêm páginas no facebook, nas quais são veiculadas informações pessoais e profissionais. Como caraterística da interface desse ambiente virtual, os seus usuários podem, a qualquer tempo e quantidade, fazer publicações escritas, imagens em foto ou vídeo e, compartilhar publicações de outros usuários com ou sem legendas próprias. Essa economia das possibilidades investe o usuário de liberdades e limitações no que tange a produção de sentidos sobre o perfil constituído em suas páginas. Isso ocorre por que, além de tecer uma rede entre as postagens, compartilhamentos e comentários com perfis de autores desconhecidos, as autoras das páginas permanecem expostas às opiniões alheias acerca das informações publicizadas $e$ reprodução de suas publicações de forma alterada ou distorcida. Esta talvez seja a característica mais atraente de participar de uma rede social virtual: compartilhar o perfil edificado e colocálo à prova de forma pública. Como analisou Sibilia (2009), seria a construção de si em interação com os outros. É possível que essa peculiaridade tenha atraído Kalil e Matarazzo, afinal, dessa maneira, suas vidas e obras poderiam reverberar com maior intensidade e, inclusive, dar-se a ver para leitores e leitoras que jamais as conheceriam se dependessem de adquirir seus livros ou ler suas colunas em revistas ou jornais. É uma estratégia de serem vistas para serem lembradas por meio desses espaços acessíveis, uma vez que, "a conjuntura atual testemunha uma volta do eu significante, visível pela profusão de escritos biográficos e autobiográficos" (CUNHA, 2007, p. 46). Aproximam-se dos diários no sentido de que são escritas de si que pretendem deixar uma marca de existência e, distanciam-se dos mesmos ao passo que são produzidos para serem publicizados. 
Glória Rodrigues Meyer Kalil, nascida em São Paulo, atuou no ramo empresarial, dedicando-se, posteriormente, ao ramo de consultoria voltada para os campos do estilo, moda e comportamento. Formada em Ciências Sociais, atuou em diversos projetos ligados ao varejo, indústria e organizações institucionais por meio de consultoria, construindo um espaço profissional no qual foi notabilizada pela perspicácia no trato às imagens individuais e coletivas. Marcou presença em diversos tipos de mídias, estendendo-se ao ambiente virtual onde participa como colunista fixa de um dos maiores serviços para internet, relacionados a conteúdos de informações e produtos. A presença significativa na televisão ampliou o escopo profissional e popularizou a imagem da autora vinculada à questão da etiqueta. Participante de programas em diversos horários, direcionados a variados grupos de telespectadores, Kalil tornou-se algo semelhante a um senso comum sobre a etiqueta e as boas maneiras na sociedade brasileira. Em 1996 publicou seu primeiro livro chamado Chic e vendeu aproximadamente cento e oitenta mil cópias, fato que a motivou a escrever outros cinco livros focados na área da etiqueta, tanto para questões de vestuário, quanto de comportamento, além de inúmeras versões pocket, revisadas e aumentadas.

Claudia Matarazzo Mieli também nasceu em São Paulo e faz parte da família de imigrantes italianos Matarazzo, a qual teve notória atuação no ramo industrial no estado. O lastro da família considerada poderosa e tradicional na sociedade paulista impulsionou a autora para atividades vinculadas ao tema da formação social. Exercendo trabalhos como jornalista, editora de revistas femininas e colunista social, Matarazzo construiu uma carreira voltada para ilustração de suas leitoras e leitores e caracterizada, como Kalil, pela versatilidade de conectarse aos novos suportes e transitar entre os vários tipos de mídias. Nessa esteira, percorrem os projetos no ambiente virtual que incluem um site oficial e cinco redes sociais nas quais a autora, possivelmente, por meio de assessoria, interage com os mais diversos grupos sociais, uma vez que, cada uma das suas redes tem características específicas que selecionam o tipo de usuário a ser conectado. No século marcado pela hiperconexão experimentada em níveis nunca antes identificados, os ecos de discursos e construções recebem quantificação contornada por estatísticas publicizadas pelas próprias redes utilizadas para veicular modos e formas de estar no mundo. Sua produção bibliográfica iniciou em 1995, com a publicação de Etiqueta sem frescura, e continuada pela produção de dezessete outros livros, ofertando, inclusive, duas publicações por ano em 2010 e 2015 .

Faz-se necessário aqui alertar que o percurso temporal das carreiras das autoras não está, necessariamente, caracterizado por um movimento evolutivo de aprimoramento das suas 
concepções acerca das boas maneiras. A transição para suportes digitais sinaliza, apenas, um movimento de adequação às conjunturas, não direcionando para hierarquias ou classificações. Assim como François Hartog ao discutir a construção da sensibilidade historiadora para a observação "de todos esses tempos folheados, imbricados, desencontrados, cada um com seu ritmo próprio" (2013, p. 37), não desejo perceber as carreiras das autoras sob um ponto de vista predominante ou cronológico e, tampouco, evolutivo. A perenidade das experiências de escrita de Kalil e Matarazzo estão marcadas pelas idas e vindas de passados e presentes que negociaram, se remodelaram e se potencializaram na hipótese que Hartog chamou de "presentismo" (2013, p. II), nesse caso, expresso pela relação virtual constituída com um sem número de interlocutores mais afeitos aos resultados estatísticos do sucesso e menos conhecedores do processo que resultou nessa prática. Os manuais de etiqueta escritos e publicados por Kalil e Matarazzo continuam e circular, talvez até com maior intensidade, por meio de suas publicações virtuais tratando assuntos do agora, circunscritas à temporalidade do virtual, marcada pelo imediatismo e pelo alcance amplificado.

No intuito de debater as estratégias mobilizadas pelas autoras para relacionar suas imagens à exemplaridade de convívio social e constituir vínculos pertinentes com passados os quais consagraram as duas mulheres como ícones de civilidade e boas maneiras, bem como, oferecer melhor visualização de alguns dados quantitativos, elaborei uma tabela ${ }^{7}$ na qual fica facilitada a visualização das aproximações.

Tabela i: O facebook das autoras em números

\begin{tabular}{|l|l|l|}
\hline $\begin{array}{l}\text { Tabela I: O facebook das autoras em númerosDados } \\
\text { retirados dos perfis do facebook das autoras. }\end{array}$ & $\begin{array}{l}\text { Gloria } \\
\text { Kalil }\end{array}$ & $\begin{array}{l}\text { Claudia } \\
\text { Matarazzo }\end{array}$ \\
\hline Número de usuários que curtiram a página. & 222.333 & 25.557 \\
\hline $\begin{array}{l}\text { Número de usuários seguidores das publicações na } \\
\text { página. }\end{array}$ & 230.319 & 25.315 \\
\hline Total de imagens publicadas pelas autoras. & 92 & 372 \\
\hline $\begin{array}{l}\text { Imagens publicadas por outros usuários no perfil das } \\
\text { autoras. }\end{array}$ & 427 & 270 \\
\hline Total de vídeos publicados pelas autoras. & 23 & 96 \\
\hline
\end{tabular}

7 Para efeito de estabilização das fontes de pesquisa, os dados da tabela foram colhidos no limite do dia 19/05/2018 às 12:00, esse fator tem relevância na medida em que a dinâmica digital modifica esses dados constantemente. As terminologias utilizadas para referenciar os dados dizem respeito às funcionalidades oferrecidas pela interface da rede social facebook. O termo "curtida" se refere aos usuários que tiveram contato visual com a publicação e tiveram reação favorável à mesma, o termo "seguidores" se refere aos usuários que optam por serem notoficados todas as vezes que o perfil for acrescido de algum conteúdo de qualquer tipo e o termo "compartilhamento" se refere à possibilidade de replicar conteúdos vistos em outros ambientes digitais. 


\begin{tabular}{|l|l|l|}
\hline $\begin{array}{l}\text { Vídeos publicados que tiveram protagonismo das } \\
\text { autoras. }\end{array}$ & 23 & $9 \mathrm{I}$ \\
\hline $\begin{array}{l}\text { Vídeos publicados que foram compartilhados de } \\
\text { outros perfis. }\end{array}$ & o & 5 \\
\hline $\begin{array}{l}\text { Total de visualizações dos vídeos protagonizados } \\
\text { pelas autoras. }\end{array}$ & $\begin{array}{l}3.778 .1 \\
\text { oo }\end{array}$ & 39.370 \\
\hline
\end{tabular}

Fonte: Tabela elaborada pela autora a partir de informações disponíveis em: https://www.facebook.com/GloriaKalilChic/ e htps://www.facebook.com/claudiamatarazzooficial

A circulação de Kalil em espaços públicos e privados de diversos tipos contribuiu na elaboração de uma performance adaptável, garantindo-lhe êxito no empreendimento nos meios digitais. A sua página no facebook, criada em 2014, registrava no dia 19/05/2018 o total de 222.333 curtidas e 230.319 seguidores. Os números inferem sobre uma interação crescente de Kalil com outros usuários da rede, uma vez que, na estabilização dos dados por ocasião da produção de uma fase anterior da pesquisa, a autora tinha em I2/09/2017, às I8:35, I42.093 curtidas e 141.702 seguidores. Considerando ainda, que houve o registro de 427 publicações de outros usuários no seu perfil, é possivel perceber um grau considerável de interlocução, destacando que ao fazer publicações no perfil da autora, outros usuários manifestam afinidades com as suas narrativas e desejam inscrever-se nas mesmas, fazendo-se presentes na fugacidade de uma publicação de redes sociais. Em ritmo desacelerado, Matarazzo, na mesma data, registrou 25.557 curtidas e 25.315 seguidores, entretanto, também registrou crescimento em relação ao ano de 2017, quando, em I2/o9/2017, às I8:33, seus números indicavam um total de 24.944 curtidas e 24.636 seguidores. Não obstante o crescimento ter sido menor, não há registro de qualquer decréscimo na questão dos usuários que seguem os perfis, pois, a interface permite que um usuário deixe de ser seguidor de algum perfil de forma rápida e fácil. Os leitores e leitoras que se aproximaram da imagem e da escrita das autoras - não necessariamente nessa exata ordem - manifestaram o desejo de continuar a acompanhar suas narrativas acerca de si e das performances sociais.

Outro dado relevante sobre a forma de dispor os ego-documentos e estabelecer interação com outros usuários é o elevado número em que as autoras protagonizam os vídeos publicados. É necessário elucidar que trata-se de filmagens que alcançam o tempo médio de, no máximo, três minutos, onde os autores dos enquadramentos e das narrações abordam algum assunto que julgam ser relevante compartilhar com outros usuários. Há uma diferença relevante do total de vídeos publicizados pelas duas autoras, no entanto, mais relevante é a proporção em que as autoras decidiram estebelecem um contato aproximado com seus seguidores, oferecendo suas 
próprias imagens e vozes como elementos narrativos. A exposição direta da imagem e da voz aproxima-se sobremaneira da concepção evidenciada por Amelang (2005) na qual aloca os egodocumentos no repertório das expressões de sentimentos e experiências pessoais. Ainda que o propósito seja disseminar práticas de civilidade vinculadas aos hábitos de círculos sociais seletos, nos quais grande parte dos interlocutores jamais esteve ou estará, a forma como sensibilizam o outro se molda a partir da forma como exprimem a significação para si.

Seria difícil persuadir o interlocutor acerca de uma imagem de qualquer tipo, se o emissor da mesma não exprimisse acolhimento e identificação. Os vídeos produzidos pelas autoras para dialogarem com os seus seguidores e outros usuários são assolados pela "tirania do instante" (HARTOG, 2013, p. Io) que faz o assunto perder o time da sua validade muito rapidamente. E, na dinâmica do mundo virtual, tanto Kalil como Matarazzo, escolheram serem as próprias narrativas, por meio da utilização, com maior ou menor grau de profissionalismo técnico, de diálogos mais pessoais possíveis, produzindo sensibilidade e identificação.

O espaço na rede privilegia as atividades profissionais das autoras, enfatizando a remodelação das civilidades e suas conexões com esse movimento. A apresentação dos assuntos à $\mathrm{O}$ espaço na rede privilegia as atividades profissionais das autoras, enfatizando a remodelação das civilidades e suas conexões com esse movimento. A apresentação dos assuntos à novas gerações é imbuída de um caráter de "novo" - autenticado pelo suporte virtual - o qual revigora o tema. Sobre ser ou não uma novidade, a discussão empreendida por Koselleck (2014, p. 2102II), na qual remonta a eventos de destaque - como, por exemplo, o Iluminismo - para discutir a configuração do "tempo novo" proveniente de determinados eventos, posteriormente pondera que o "novo" de cada tempo é dotado de historicidade, portanto relativo. A adaptação das autoras ao suporte virtual destaca como encontraram formas de continuidade para suas produções bibliográficas. Sob roupagem moderna das tecnologias de comunicação e informação, Kalil e Matarazzo continuam a veicular suas prescrições sobre comportamentos e convivência, como nos manuais da década de 1990. A quantidade de visualizações dos vídeos de cada uma das autoras é indício da amplificação da circulação de suas discussões sobre etiqueta e as boas maneiras. Adapatada ao suporte e ao tempo, Gloria Kalil ascende a uma popularidade virtual considerável, haja vista que sua produção bibliográfica seria reproduzida de forma mais lenta, mesmo títulos considerados best sellers. Com a marca de 3.778.10o de visualizações em apenas 23 vídeos, a autora se destaca como ícone no tratamento de temas relativos a civilidade. 
Algumas considerações

Um tempo compreendido pela percepção de Koselleck (2006), o qual se produz na tensão entre o espaço de experiência e o horizonte de expectativa, portanto, um tempo histórico, é o espaço possível para a constituição das relações sem materialidade, sem contato físico e com muitas incertezas. Alocadas nesse tempo, cada autora se legitimou em seu lugar de fala, bem como, delimitou a forma como quiseram se mostrar e estabelecer diálogos, porém ainda no âmbito das experimentações. A peculiaridade de cada percurso evidenciou a quantidade de dobras sob as quais se constroem as temporalidades e o quanto é necessário aproximar-se ao máximo para perceber as sensíveis condições que estruturam as relações estabelecidas por meio de espaços virtuais. Essas autoras registraram na rede as formas como querem ser reconhecidas e lembradas, arriscando-se no limiar entre o publicado e o compartilhado, o qual experimenta toda sorte de possibilidades de interlocução. A relação temporal vislumbrada nas páginas das autoras por este estudo é apenas um olhar possível.

As estratégias diferenciadas de cada uma das autoras aponta para opções de dar-se a ver. Dentre as múltiplas possibilidades da rede, Kalil e Matarazzo escolheram como querem mostrar-se e as formas de exibição constituem elementos relevantes na definição de espaços e representações. Apenas com dados virtuais me permiti colocar Gloria Kalil sob o status de ícone nos assuntos de etiqueta e boas maneiras. A construção de entendimentos possíveis acerca de determinados processos esbarra nas questões levantadas por Sibilia acerca das redes sociais, "ser, ter ou parecer?” (2009, p. 319). Ocupando irremediavelmente esses espaços as autoras perpetuam suas perspectivas e dão nova cor aos temas, o importante é fazer-se presença para tornar-se representação. A demanda formativa estimulada por um processo civilizador em curso dá fôlego aos produtores de narrativas e a integração das práticas válidas e vigentes mostra vitalidade perante as constantes transformações. Ser seguidor de uma autora proeminente em números não é garantia de internalizar os melhores preceitos de civilidade, entretanto, dá lastro de pertencimento a um grupo que se quer definir como informado e conectado.

Uma estatística possível, no sentido de evidenciar os usuários que leram as postagens, seria quantificar os comentários escritos nas caixas de mensagens alocadas abaixo de cada postagem feita, todavia, a interlocução efetiva não compreende os objetivos desse estudo, o qual está concentrado sobre a forma como as autoras se dão a ver em suas páginas. Em uma possível reverberação da temporalidade do virtual marcada pelo agora, as páginas das autoras concentram a maior parte de suas publicações em eventos ocorridos em um tempo próximo, mantendo assim o time da internet. 
As diversas publicações das autoras evidenciam as peculiaridades das trajetórias que têm em comum a produção de escritas formadoras e a socialização de suas vivências como forma de legitimar suas obras e continuar subsidiando formação por meio de outros suportes. A questão da formação não se reporta a um todo, mas, a um grupo que cria identificação e, portanto, se distingue de outros pelo modo e pela forma. A contabilização das "curtidas", dos "seguidores" e das "visualizações" são indiciários da forma como cada autora construiu sua identificação junto aos interlocutores ativos no meio virtual. Sobre essa relação, as estratégias de construção de si de cada uma das autoras determinou essa contabilidade, inscrita em um lógica própria de desenvolvimento. A quantidade de publicações não é proporcional a quantidade de seguidores, portanto há critérios de identificação nesse ambiente que ainda carecem de estudos. Cada autora delineou o grupo com o qual dialogava, configurado a partir das suas vivências, formações, relações profissionais. Suas páginas não foram criadas para serem, propriamente, escritas de si, entretanto, foram escritas sobre si no tempo e no espaço.

\section{Referências}

AMELANG, James S. Presentación - Dossier: De la autobiografia a los ego-documentos: un fórum abierto. Cultura Escrita \& Sociedad, n. ${ }^{\mathrm{o}}$ I, p.17-18, sep./2005.

ARTlÈRES, Philippe. Arquivar a própria vida. Estudos Históricos, v. II, n. 2I, p.9-34, I998. Disponível em: http://bibliotecadigital.fgv.br/ojs/index.php/reh/article/view/2061/r200. Acesso em: 30 abr. 2019.

CUNHA, Maria Teresa Santos. Do baú ao arquivo: escritas de si, escritas do outro. Revista Patrimônio e Memória, v.3, n.I, p. 45-62, 2007. Disponível em: http://pem.assis.unesp.br/index.php/pem/article/view/8/455. Acesso em: I5 out. 2019.

- O arquivo pessoal do professor catarinense Elpídio Barbosa (1909-1966): do traçado manual

ao registro digital. História da Educação, v. 21, p. 187-206, 2017. Disponível em: http://www.scielo.br/pdf/heduc/v2In5I/2236-3459-heduc-2I-51-00187.pdf . Acesso em: is out. 2019.

DOSSE, François. O acontecimento-monstro. In.: Dosse, François. Renascimento do acontecimento um desafio para o historiador: entre Esfinge e Fênix. São Paulo: Editora UNESP, 2013, p. 259-277.

Entrevista com o historiador Henry Rousso. (Por Sílvia Maria Fávero Arend e Fábio Macedo). Tempo \&Argumento. Florianópolis, v.I, n.I, p.201-216, jan/jun.2009. Disponível em: http://www.revistas.udesc.br/index.php/tempo/article/view/705/608 Acesso em: I6 jun. 2019.

ELIAS, Norbert. O Processo Civilizador. Volume 2: Formação d Estado e Civilização. Rio de Janeiro: Jorge Zahar Editor, 1993. 
HARTOG, François. Regimes de historicidade: presentismo e experiências do tempo. Belo Horizonte: Autêntica Editora, 2013.

KOSELLECK, Reinhat. Futuro passado: contribuição à semântica dos tempos históricos. Rio de Janeiro: Contraponto/Editora PUC-Rio, 2006.

MIGNOT, Ana Chrystina Venancio; BASTOS, Maria Helena Camara; CUNHA, Maria Teresa Santos.Refúgios do eu: educação, história, escrita autobiográfica. Florianópolis: Mulheres, 20oo.

ROUSSO, Henry. The Vichy Syndrome: History and Memory in France since 1944. Cambridge, MA and London: Harvard University Press, 1991.

SIBILIA, Paula. Em busca del aura perdida: espectacularizar la intimidad para ser alguien. Psicoperspectivas, V1ll, $\mathrm{n}^{-}$2 (Julio-Diciembre), 2009), p.309-329. Disponível em: http://www.psicoperspectivas.cl/index.php/psicoperspectivas/article/viewFile/83/82 Acesso em: 30 abr.2019. 